\title{
Altitude-related deaths in seven trekkers in the Himalayas
}

\author{
JOHN DICKINSON, DONALD HEATH, JOHN GOSNEY, DAVID WILLIAMS \\ From the Shanta Bhawan Hospital, Kathmandu, Nepal; and the Department of Pathology, University of \\ Liverpool
}

ABSTRACT The clinical features and necropsy findings are described for seven trekkers in the Himalayas whose deaths were related to high altitude. The fatal outcome was due to serious pulmonary and cerebral disease. Oedema of the lungs and brain was prominent but so was thrombosis and haemorrhage, features of acute mountain sickness that have received insufficient recognition in the past. Most of the men were middle aged. Some began their trekking soon after flying to high altitude before becoming acclimatised and some remained at high altitude or climbed even higher despite the development of vomiting, breathlessness, and exhaustion. In one case death occurred despite prompt recognition and treatment of symptoms by administration of oxygen and swift evacuation to low altitude.

Trekking holidays in the Himalayas are becoming increasingly popular and attract many tourists, often middle aged, to the high mountains. Not infrequently they are transported rapidly by aeroplane to altitudes of $3000 \mathrm{~m}$ or more, to begin their trek unacclimatised to the hypobaric hypoxia. On the Everest Base Camp route, heights of up to $5800 \mathrm{~m}$ may be achieved without mountaineering or even scrambling.' About half of the trekkers (53\%) will experience acute mountain sickness of some degree. $^{2}$ A minority (4.3\%) will develop life threatening illness. ${ }^{2} \mathrm{~A}$ few will die as a result of their exposure to hypobaric hypoxia. Clearly medical advice before people embark on such a trekking holiday to high altitude is desirable, yet many medical practitioners are totally unaware of the serious pulmonary and cerebral disease that may overtake a minority of those visiting high places and have little or no idea of what advice to give. It is noteworthy that three of the seven men with fatal acute mountain sickness we report here were doctors (cases 3, 5, and 7). In this paper we give brief clinical summaries and the salient features at necropsy for seven men who died while trekking in the Himalayas. All but one survived long enough to be treated on their des-

Address for reprint requests: Professor D Heath, Department of Pathology, University of Liverpool, PO Box 147, Liverpool L69 3BX.

Accepted 7 June 1983 cent from the mountains at Shanta Bhawan Hospital, situated at an altitude of $1370 \mathrm{~m}$ in Kathmandu, Nepal.

\section{The case histories}

CASE 1

Clinical summary A man aged 54 left Kathmandu on 25 September 1974 to trek into the Solu Khumbu. From his first exposure to a considerable altitude $(3660 \mathrm{~m})$ on 3 October he climbed with the party, to cross the Tesi Lapcha pass $(5700 \mathrm{~m})$ on 8 October. The next day he climbed a peak of 6300 $\mathrm{m}$ and then descended to reach Namche Bazaar $(3440 \mathrm{~m})$ four days later. Then he became ill with a slight cough, breathlessness on walking, and anorexia. A slight headache developed and shortly afterwards vomiting and regurgitation of fluids. On two occasions he "collapsed," remaining conscious but feeling very weak. He was carried down to the airstrip at Lukla $(2800 \mathrm{~m})$ and was flown to Kathmandu on 17 October.

On examination he was conscious and orientated but was very weak. His temperature was $38.5^{\circ} \mathrm{C}$, his radial pulse 100 beats $/ \mathrm{min}$, and his systemic blood pressure $90 / 70 \mathrm{~mm} \mathrm{Hg}$. The optic fundi showed moderate papilloedema but no haemorrhages. There was slight nystagmus at the extremity of gaze to both sides. The knee and ankle jerks could not be elicited. A chest radiograph showed no abnormality. An electrocardiogram taken later showed a sinus tachycardia which had increased to 160 beats $/ \mathrm{min}$. 646 
Table 1 Pathological findings in lungs and brain

\begin{tabular}{|c|c|c|c|c|c|c|c|c|c|}
\hline \multirow{2}{*}{$\begin{array}{l}\text { Case } \\
\text { No }\end{array}$} & \multirow{2}{*}{$\begin{array}{l}\text { Age } \\
\text { (y) }\end{array}$} & \multicolumn{4}{|l|}{ Lungs } & \multicolumn{3}{|l|}{ Brain } & \multirow{2}{*}{$\begin{array}{l}\text { Deep vein } \\
\text { thrombosis }\end{array}$} \\
\hline & & $\begin{array}{l}\text { Pulmonary } \\
\text { thrombosis }\end{array}$ & $\begin{array}{l}\text { Red } \\
\text { infarcts }\end{array}$ & $\begin{array}{l}\text { Broncho- } \\
\text { pneumonia }\end{array}$ & Oedema & Thrombosis & Haemorrhage & Oedema & \\
\hline$\frac{1}{2^{*}}$ & $\begin{array}{l}54 \\
38\end{array}$ & $\stackrel{+}{++}$ & $\begin{array}{l}0 \\
++\end{array}$ & $\begin{array}{l}++ \\
+\end{array}$ & $\stackrel{+}{\circ}$ & $\begin{array}{l}\text { O } \\
\text { Subarachnoid } \\
\text { venous with } \\
\text { haemorrhage. } \\
\text { Petechiae. }\end{array}$ & $\begin{array}{l}0 \\
+\end{array}$ & $\begin{array}{l}++ \\
0\end{array}$ & $\begin{array}{l}\circ \\
\circ\end{array}$ \\
\hline 3 & 27 & ++ & ++ & + & 0 & $\begin{array}{l}\text { Venous with } \\
\text { subarachnoid } \\
\text { haemorrhage. } \\
\text { Posterior dural } \\
\text { venous sinuses. }\end{array}$ & $\begin{array}{l}+ \\
1 \\
1\end{array}$ & + & O \\
\hline $\begin{array}{l}4 \\
5^{*} \\
6 \\
7\end{array}$ & $\begin{array}{l}54 \\
41 \\
46 \\
62\end{array}$ & $\begin{array}{l}++ \\
0 \\
0 \\
++\end{array}$ & $\begin{array}{l}+ \\
0 \\
0 \\
0\end{array}$ & $\begin{array}{l}++ \\
+ \\
+ \\
+\end{array}$ & $\begin{array}{l}0 \\
++ \\
++ \\
++\end{array}$ & $\begin{array}{l}0 \\
0 \\
0 \\
\ldots\end{array}$ & $\begin{array}{l}0 \\
+ \\
0 \\
\cdots\end{array}$ & $\begin{array}{l}+ \\
++ \\
++ \\
\ldots\end{array}$ & $\begin{array}{l}+ \\
0 \\
0 \\
0\end{array}$ \\
\hline
\end{tabular}

${ }^{*}$ Cases 2 and 5 have been previously reported by Houston and Dickinson ${ }^{13}$ and included in a DM thesis accepted by the University of Oxford, 1982.

He was treated with procaine penicillin but deteriorated. The white cell count rose to $27.2 \times$ $10 \%$ with $85 \%$ neutrophils. Treatment was started with intravenous betamethasone and ampicillin to control cerebral oedema and possible bacterial infection. The following day he became anuric and developed Cheyne-Stokes breathing. The pupils became narrow and slight neck stiffness developed. Consciousness became impaired, with reaction to pain only but not to command. There were no localising signs in the central nervous system. The spinal fluid was normal and its pressure was $25 \mathrm{~cm}$ $\mathrm{H}_{2} \mathrm{O}$. Intravenous mannitol and glycerol by nasogastric tube were given but there was no clinical improvement and consciousness deteriorated. His systemic blood pressure fell and he died on 21 October.

Necropsy findings (table 1) The brain was oedematous but showed no haemorrhage. There was no cerebral thrombosis and no abnormality of the cerebral vasculature. The lungs were oedematous and there was severe bronchopneumonia. At the right base there were pleural adhesions with a small pleural effusion but the left pleural cavity was dry. Recent thrombi were present in the pulmonary arteries (fig 1). The heart appeared normal macroscopically and there was no coronary thrombosis.

\section{CASE 2}

Clinical summary A man aged 38 flew from Kathmandu $(1370 \mathrm{~m})$ to Lukla $(2800 \mathrm{~m})$ on 11 April 1972 and on the same day walked to Namche Bazaar (3440 m). In February of the previous year he had climbed Mt Kilimanjaro $(5900 \mathrm{~m})$ and Mt Cameroun $(4060 \mathrm{~m})$ "very fast" without any ill effects. Over the next three days while trekking to
Lobuche $(4920 \mathrm{~m})$ he lost his appetite, felt nauseated, and began to vomit. On the following day he climbed to Gorakshep $(5200 \mathrm{~m})$ but felt weak. On the next day he attempted to climb

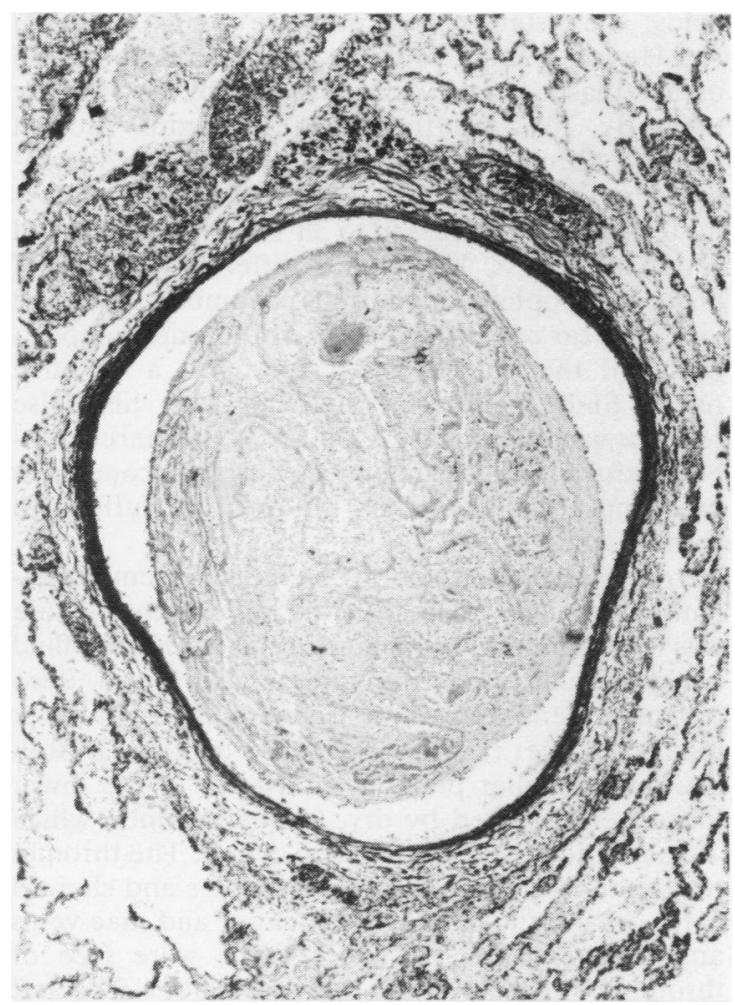

Fig 1 Case 1: transverse section of muscular pulmonary artery that contains a recent antemortem thrombus. (Elastic Van Gieson, ×60.) 
Kalapattar ( $5540 \mathrm{~m})$ but felt so weak that he gave up the attempt. On 17 April two tourists found him back at Gorakshep and reported his illness to two German doctors at Everest Base Camp, who attended him. He was vomiting and showed weakness and stupor. He passed less urine than normal and intermittently drifted into unconsciousness. His pulse rate was 128 beats/min and his systemic blood pressure was $100 / 60 \mathrm{~mm} \mathrm{Hg}$. Crackles were heard on both sides of the chest and he coughed weakly. He was given oral potassium chloride, intramuscular strophanthin and hydrocortisone, and.diazepam. On 19 April he was carried down to Namche Bazaar and received oxygen $(3 \mathrm{l} / \mathrm{min})$. The following day he was transferred by helicopter to Shanta Bhawan in Kathmandu.

On examination he was deeply unconscious with stertorous breathing. The limbs were flaccid and only the knee jerks were obtainable. Both plantar responses were extensor. The pupils were equal and reactive. The optic discs were pink and poorly defined and there were multiple flame-shaped haemorrhages in both eyes. The lungs were full of coarse crepitations, audible throughout both lung fields. The systemic blood pressure was $140 / 100 \mathrm{~mm}$ $\mathrm{Hg}$. He was treated with intravenous frusemide and betamethasone and with glycerol by nasogastric tube. By 20 April the chest radiograph showed bilateral diffuse infiltrations and penicillin and streptomycin were administered. Over the next two days his temperature increased to $38.9^{\circ} \mathrm{C}$ with a white cell count of $21.4 \times 10^{\%} / 1$ and a differential count of $80 \%$ neutrophil polymorphs. Lumbar puncture yielded clear cerebrospinal fluid of normal composition and the Queckenstedt test gave a negative result. Suddenly on the following day his pulse became weaker and the blood pressure unrecordable. Respiration became irregular and coma was profound. At 6.30 am on 26 April he suffered a cardiac arrest.

Necropsy findings (table 1) At postmortem examination there was cyanosis of the lips and ears. There was bilateral basal bronchopneumonia. Frothy fluid could be expressed from the small bronchi. Two pyramidal red infarcts were found in the right lower lobe, the larger measuring $9 \times 7.5 \mathrm{~cm}$ (fig 2). Both main and smaller pulmonary arteries to the lower lobes were blocked by dry, friable thrombi, which were mottled red and yellow in colour. The thrombi projected from the pulmonary arteries and showed early organisation. The venae cavae and iliac veins and the veins of the lower limbs were free of thrombi. The heart $(395 \mathrm{~g})$ was dilated. The left coronary artery was almost occluded at two points, in the anterior descending branch $3 \mathrm{~cm}$ from its origin and in the circumflex branch $2.7 \mathrm{~cm}$ from its origin, where the lumen was hardly visible. Histological examination confirmed the presence of calcified atheromatous plaques. The brain $(1450 \mathrm{~g})$ was not oedematous but the cerebral blood vessels were congested. Over the right cerebral hemisphere were several dark red haemorrhages into the subarachnoid space, the largest of which was in the Sylvian and inferior Rolandic fissures and measured $5 \times 3.5$ $\mathrm{cm}$. Subarachnoid veins were distended and contained antemortem thrombus. There was a haemorrhage measuring $17 \times 8 \mathrm{~mm}$ in the subcortical matter of the right parietal lobe. Foci of degeneration were seen in the adjacent brain substance. Smaller haemorrhages and petechiae were found in the subcortical white matter of the cerebrum, corpus callosum, pons, and cerebellum. Sites of older haemorrhage were indicated by focal collections of compound granular corpuscles and haemosiderin.

\section{CASE 3}

Clinical summary A young Swiss physician aged 27 joined a climbing expedition as its medical

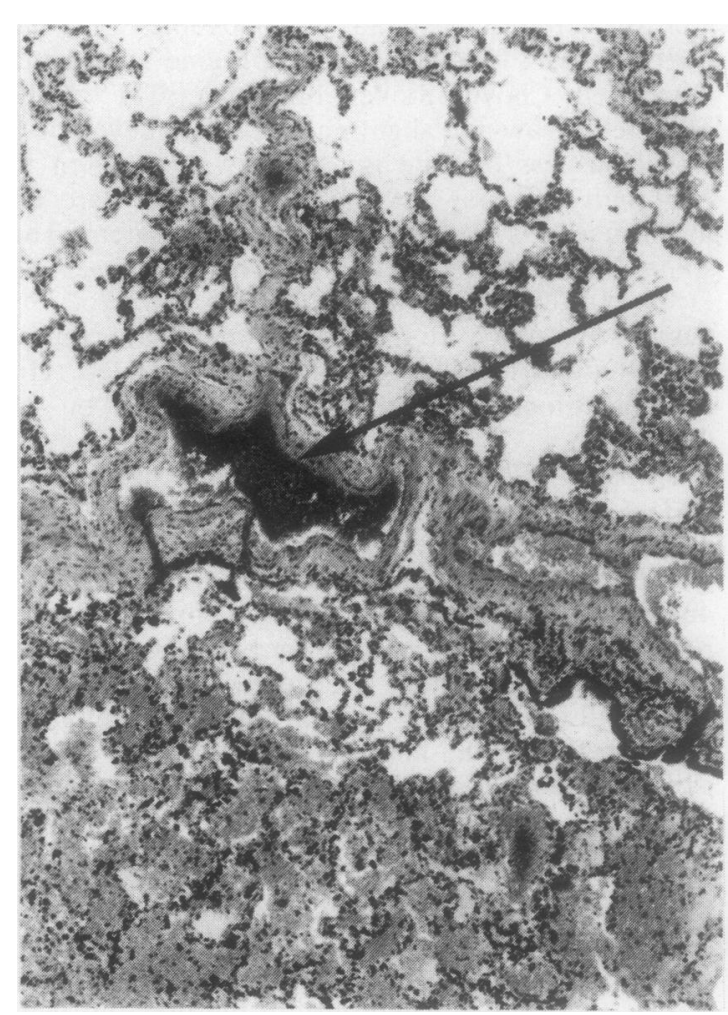

Fig 2 Case 2: a muscular pulmonary artery, cut in longitudinal section, containing a recent thrombus (arrow); beneath the vessel is the edge of a red infarct. (Haematoxylin and eosin, $\times 60$.) 
officer, although he had no experience of mountaineering or high altitude. He ascended to Pumori base camp $(5180 \mathrm{~m})$, where he remained for three weeks. He did not acclimatise well and was inactive and his gait was unsteady. He had difficulty in sleeping and had sedatives for this and he took amphetamines during the day to counteract the effect of the sleeping pills. On 21 October 1978 he felt too unwell to remain at the camp and began to walk down but was too ill to continue and climbed back up to base camp at $5180 \mathrm{~m}$. Overnight he became unconscious and the next day he was carried down to Pheriche $(4260 \mathrm{~m})$. Here he came under the care of a visiting university research team, who found him to be deeply unconscious with fixed, dilated pupils, papilloedema, and retinal haemorrhages. Urinary catheterisation yielded 1 litre of urine. He was treated with oxygen, which maintained arterial saturation at $90-95 \%$ (ear oximetry). $\mathrm{He}$ was also given dexamethasone and intravenous acetazolamide $(500 \mathrm{mg})$. His systemic blood pressure was $90 / 65 \mathrm{~mm} \mathrm{Hg}$. The following day he was evacuated by helicopter to Shanta Bhawan (1370 $\mathrm{m})$. The chest radiograph showed some haziness, of doubtful significance, on the left side but there was no evidence of gross pulmonary oedema. His white cell count was $14.1 \times 10^{9} / 1$ with $80 \%$ neutrophils. Treatment with steroids was continued and he was also given mannitol. After seven hours his blood pressure began to fall and he became pulseless and died.

Necropsy findings (table 1) The body was obese and the face dusky grey with cyanotic lips. The dura was normal but the posterior and transverse dural venous sinuses on both sides contained thrombus, which showed no evidence of organisation. Veins in the subarachnoid space overlying the cerebral cortex were distended by thrombus and there was much haemorrhage into the subarachnoid space. The brain $(1720 \mathrm{~g})$ showed swelling and flattening of the gyri with compression of the sulci. There was moderate bulging of the unci, cingulate gyri, and cerebellar tonsils. All portions of the brain showed oedema of variable degree with spongiosis of the tissues, greatest in the basal ganglia and white matter generally. There were extensive areas of haemorrhagic infarction and associated oedema in the cerebral cortex, subcortical white matter, and brain stem. The parenchyma of the right $(575 \mathrm{~g})$ and left lung $(550 \mathrm{~g})$ was pink, soft, and compressible. Both lower lobes were firm and oedematous and were the site of several pyramidal red infarcts, the apices extending towards the hilum. The pulmonary arteries to these lobes were distended with firm thrombi protruding above the cut surface. Thrombus was also present in the artery to the right upper lobe. Histological examination showed that most of the thrombi were recent but a few showed early organisation. There was acute suppurative bronchiolitis and early bronchopneumonia. The heart $(390 \mathrm{~g})$ showed no abnormality.

CASE 4

Clinical summary A man aged 54 who was accustomed to cross country running flew to Jiri and trekked from there to the Khumbu region. He walked very fast and hard and twice bathed in glacial rivers. After the second bathe, at $2440 \mathrm{~m}$, he became ill with tiredness and shortness of breath. He continued to ascend to Namche Bazaar (3440 m) but then was evacuated to lower altitude by aircraft. On admission to hospital on 29 October 1974 he was dyspnoeic, tachypnoeic $(40 / \mathrm{min})$, and drowsy. There were crepitations at the left axilla. Initially the temperature was $37 \cdot 8^{\circ} \mathrm{C}$ but was subsequently normal. The radial pulse rate was $100 / \mathrm{min}$ and the systemic biood pressure $110 / 40 \mathrm{~mm} \mathrm{Hg}$. The left foot and calf were oedematous, the calf muscles were tender, and Homan's sign was positive. A few splinter haemorrhages were present in the fingernails but these were regarded as being due to trauma. A chest radiograph taken on admission showed no abnormality. The white cell count was $21 \times 10 \%$ with $88 \%$ neutrophils. He developed tremor and a right extensor plantar response. The fundi appeared normal. Treatment was started with intravenous heparin and with warfarin, intravenous betamethasone, and ampicillin in full doses. He deteriorated and had such difficulty in expectoration that tracheostomy had to be performed. Secretions from the lung yielded penicillin-resistant staphylococci. The next day he suffered a cardiac arrest.

Necropsy findings (table 1) The lips and nails were cyanosed. Both lungs showed extensive confluent bronchopneumonia, only the anterior aspects of the upper lobes remaining aerated (fig 3 ). There were small effusions of bloody fluid in both pleural cavities. Both lower lobes contained red infarcts. Thrombi were present in all the lobar pulmonary arteries except those supplying the right middle lobe. That in the right lower lobe artery was especially prominent. The heart $(360 \mathrm{~g})$ was normal apart from slight dilatation of the right ventricle. The coronary arteries were widely patent and not appreciably atherosclerotic. The brain was oedematous and showed spongiosis (fig 4). The dura mater and dural sinuses were normal.

CASE 5

Clinical summary A Polish doctor aged 41 was climbing in the vicinity of Pangboche in the Everest area in 1972 when he became ill. His condition 


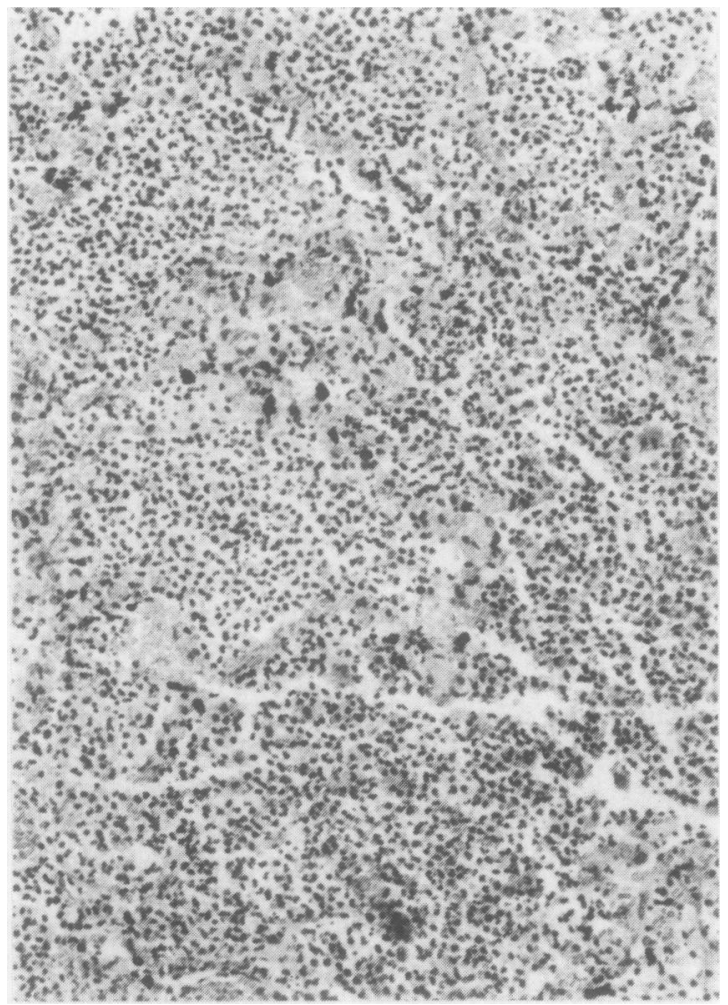

Fig 3 Case 4: confuent bronchopneumonia, the alveolar spaces being packed with neutrophil polymorphonuclears. (Haematoxylin and eosin, $\times 60$.)

became progressively worse at Pheriche $(4260 \mathrm{~m})$, which was the highest point he reached. He was brought down to Namche Bazaar and evacuated to Kathmandu by helicopter. By the time he reached Shanta Bhawan Hospital he was dead.

Necropsy findings (table 1) The face and fingertips were cyanosed. The brain $(1970 \mathrm{~g})$ showed gross cerebral oedema with swelling and flattening of the gyri and narrowing and compression of the sulci. There was pronounced herniation of the cerebellar tonsils and unci with the cingulate gyri affected to a less degree. Spongiosis was most prominent in the white matter of the brain, particularly in the medulla, but was also apparent in the grey matter and various nuclei. The meningeal blood vessels were congested. Numerous petechiae and larger haemorrhages with focal destruction. of tissue were seen throughout the white matter (fig 5). They were especially prominent in the corpus callosum but the cortical grey matter and basal ganglia were largely spared. The central and dependent portions of the lungs were grossly oedematous and frothy fluid

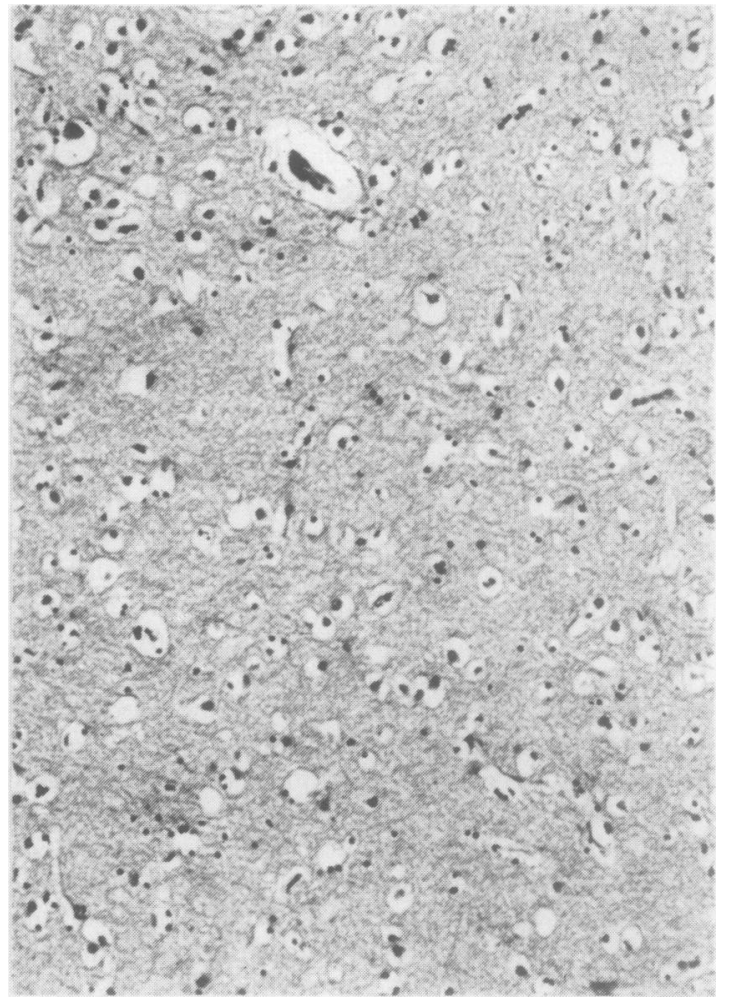

Fig 4 Case 4: spongiosis due to cerebral oedema. (Haematoxylin and eosin, $\times 150$.)

oozed from the cut surface of the lungs and bronchi. Histological examination showed intense pulmonary capillary congestion and focal collapse of alveolar spaces filled with proteinaceous fluid containing macrophages and erythrocytes. Many of the alveolar spaces were lined by fibrin. No thrombi or emboli were present in the pulmonary arterial tree. The heart $(510 \mathrm{~g})$ was moderately dilated and petechial haemorrhages were present in the epicardium. There was atherosclerosis of the coronary arterial tree with narrowing of the left anterior descending coronary artery to about half of the normal diameter.

\section{CASE 6}

Clinical summary A man aged 46 left Kathmandu on 2 April 1979, and did the trek up the Trisuli Valley on 3-5 April. He was not well even at low altitude $(2000 \mathrm{~m})$ and became tired and anorexic and began to vomit. Two days later at Langtang village $(3650 \mathrm{~m})$ he became unconscious and was evacuated to Kathmandu. On admission to hospital 


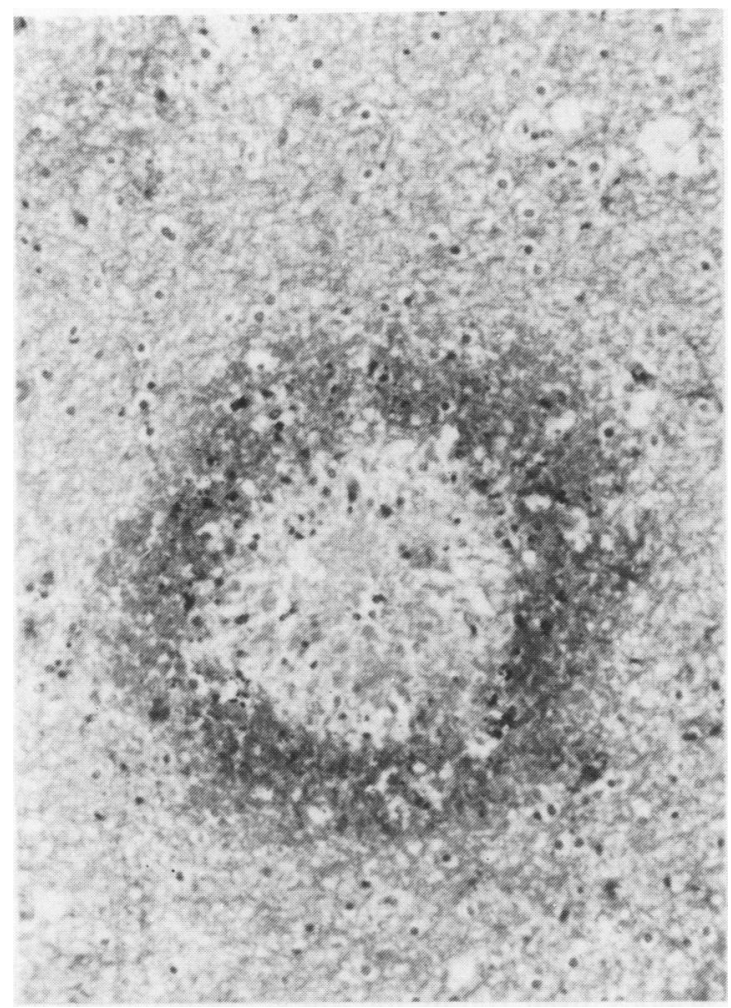

Fig 5 Case 5: petechial haemorrhage in the brain. (Haematoxylin and eosin, $\times 150$.)

he was deeply unconscious, responding only to pain. He was cyanosed but was hyperventilating. Crackles and rhonchi were heard throughout the lungs. The pupils were constricted and after dilatation showed papilloedema and several retinal haemorrhages. The respiratory rate was $40 / \mathrm{min}$. The temperature was $40^{\circ} \mathrm{C}$ and the pulse rate $120 / \mathrm{min}$. The systemic blood pressure was $90 / 70 \mathrm{~mm} \mathrm{Hg}$. On 9 April the white cell count was $32 \times 10^{\%} / 1$ with $71 \%$ neutrophils. An endotracheal tube was passed and oxygen was administered. For a short time he was given positive pressure ventilation. His pulmonary signs improved quite rapidly but he remained unconscious. After 18 hours he became anuric. Treatment with doses of frusemide up to $1 \mathrm{~g}$ intravenously failed to produce a diuresis. He also received intravenous ampicillin but died after a cardiac arrest on 11 April.

Necropsy findings (table 1) The lips and nail beds were cyanotic. Oedema affected all but the anterior portions of the middle and lower lobes of the right lung $(990 \mathrm{~g})$ but was confined to the posterior halves of the lobes of the left lung (740 g). An abundant, thin, frothy red fluid oozed from the cut surfaces of the bronchi and lung parenchyma. On histological examination the alveolar spaces were obliterated by proteinaceous fluid and there was early bronchopneumonia. No thrombi were found in the pulmonary arterial tree. The heart $(390 \mathrm{~g})$ showed no abnormality apart from slight atherosclerosis of the coronary arteries. The brain $(1685 \mathrm{~g})$ was séverely oedematous with swollen gyri and narrowed sulci. There was slight herniation of the cerebellar tonsils and the unci, but there was little or no bulging of the cingulate gyri. On histological examination the brain showed moderate generalised spongiosis; this was most pronounced in the cerebral white matter. Multiple transection of the brain showed no evidence of haemorrhage and there was no thrombosis in the cerebral arteries.

\section{CASE 7}

Clinical summary In February 1973 a 62 year old Austrian doctor had been evacuated from Mount Kenya with a diagnosis of pulmonary oedema, which improved at once on descent. He was told he had systemic hypertension $(180 / 80 \mathrm{~mm} \mathrm{Hg})$ and had been put on treatment for this. On 10 April he flew to Jiri and then trekked to the Khumbu region, ascending rapidly to Gorakshep $(5200 \mathrm{~m})$ and arriving there on 20 April. While descending to Thyangboche $(3880 \mathrm{~m})$ he became very dyspnoeic and developed a dry cough. His urinary output appeared to be adequate and increased after frusemide injections given by a medically qualified companion. On 23 April he was flown back to Lukla $(2800 \mathrm{~m})$ and then to hospital at Kathmandu (1370 $\mathrm{m})$, where he remained dyspnoeic and moderately cyanosed.

He was pale and sweating. His radial pulse rate was $120 / \mathrm{min}$ and the systemic blood pressure was $150 / 70 \mathrm{~mm} \mathrm{Hg}$. There were coarse crepitations which obscured the heart sounds. The optic discs were blurred but there were no retinal haemorrhages. His white cell count was $20.3 \times 10^{9} / 1$ with $93 \%$ neutrophils. The erythrocyte sedimentation rate was $28 \mathrm{~mm}$ in one hour. A portable radiograph of the chest showed extensive infiltrations in both lung fields, the left being affected more than the right. The transverse cardiac diameter was increased. An electrocardiogram showed a sinus rhythm of 128 beats/min and an incomplete left bundle block pattern. In view of the fall of systemic blood pressure and the failure to improve on descent to a lower altitude, he was thought to have pulmonary oedema due to myocardial infarction rather than to high altitude disease. He was treated with continuous oxygen by nasal catheter and then by 


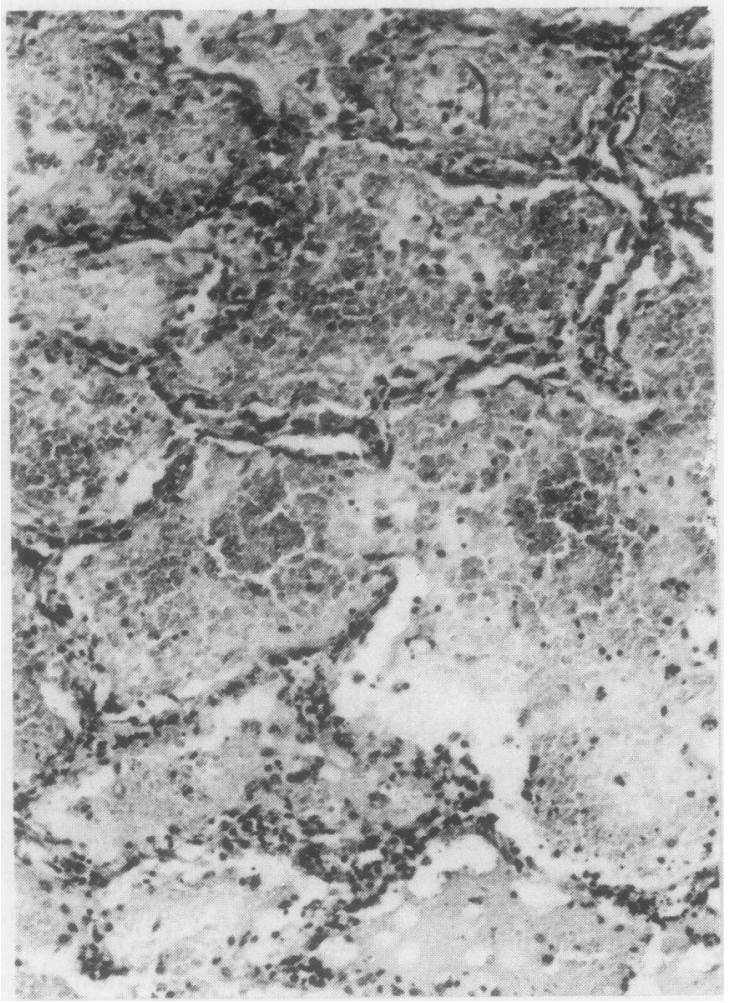

Fig 6 Case 7: section of lung showing high altitude pulmonary oedema; the alveolar spaces are distended with blood stained oedema ftuid. (Haematoxylin and eosin, $\times 150$.)

mask but this failed to relieve the cyanosis. Intravenous frusemide and aminophylline produced symptomatic relief and a good diuresis. Intravenous morphine was also given, with only temporary relief of dyspnoea; and he also received intramuscular digoxin and ampicillin. Despite these measures he was worse the next day and 26 hours after admission he was found pulseless and apnoeic.

Necropsy findings (table 1) The lips and nail beds were cyanotic. Both lungs were severely oedematous, the left weighing $1310 \mathrm{~g}$ and the right $1000 \mathrm{~g}$. Abundant frothy pink fluid oozed from the lung parenchyma and bronchial tree. The alveolar spaces were distended by oedema fluid (fig 6) and in focal areas contained fibrin, red cells, and neutrophil polymorphs. There was widespread bilateral bronchopneumonia with areas of consolidation. The major branches of the pulmonary arteries to the left lower, right lower, and right upper lobes were distended with antemortem thrombi, which protruded from the cut surface of the vessels. The thrombi were adherent to the intima with marginal organisation by fibroblasts, suggesting that they were autochthonous rather than embolic in nature, since only four days elapsed from the time of onset of symptoms until death. The heart was enlarged $(470 \mathrm{~g})$ and the right side was moderately dilated. The coronary arteries showed moderate atherosclerosis but there was no myocardial infarction. The skull was not opened at necropsy.

\section{Pulmonary vascular pathology}

In all cases the medial thickness of pulmonary arteries, from 100 to $500 \mu \mathrm{m}$ in external diameter, was examined in the paraffin sections of available blocks of tissue. The medial thickness was expressed as a percentage of the external diameter of the vessel examined. The lung tissue had been fixed in the collapsed state in $10 \%$ formalin in the hospital laboratory at Kathmandu. Up to 50 arteries were available for study in each case. Arteries in this range of diameter are classified as "muscular pulmonary arteries." Measurement of their medial thickness is a simple matter, for the clearly delineated media of circularly orientated smooth

Table 2 Measurements of pulmonary arteries and veins

\begin{tabular}{|c|c|c|c|c|c|}
\hline \multirow[t]{3}{*}{ Case No } & \multicolumn{3}{|c|}{ Muscular pulmonary arteries } & \multicolumn{2}{|c|}{ Pulmonary veins } \\
\hline & \multicolumn{2}{|c|}{ Medial thickness (\%) } & \multirow[t]{2}{*}{ Thrombosis } & \multicolumn{2}{|c|}{ Medial thickness (\%) } \\
\hline & Range (SD) & Mean & & Range (SD) & Mean \\
\hline $\begin{array}{l}1 \\
2 \\
3 \\
4 \\
5 \\
6 \\
7 \\
\text { Normal values } \\
\text { at sea level }\end{array}$ & $\begin{array}{l}1 \cdot 1-8.4(1 \cdot 8) \\
2.9-6.1 \\
1.4-7.6 \\
1.4-8.7 \\
2 \cdot 2-9.9 \\
1 \cdot 7-1 \cdot 3) \\
2 \cdot 0-11.4(2.8) \\
2 \cdot 8-6.8 *\end{array}$ & $\begin{array}{l}4.2 \\
3.7 \\
2.9 \\
2.8 \\
3.8 \\
3.8 \\
6.0\end{array}$ & $\begin{array}{l}+ \\
+ \\
+ \\
+ \\
0 \\
0 \\
+\end{array}$ & 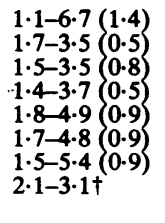 & $\begin{array}{l}2.9 \\
2 \cdot 3 \\
1.9 \\
2 \cdot 2 \\
2.9 \\
2 \cdot 6 \\
2.7 \\
2 \cdot 6\end{array}$ \\
\hline
\end{tabular}

None of the cases showed muscularisation of pulmonary arterioles.

"From Harris and Heath ${ }^{3}$

†From Wagenvoort and Wagenvoort." 
muscle is bounded by sharply defined inner and outer elastic laminae. The mean medial thickness of muscular pulmonary arteries in each of the seven cases is shown in table 2 . In none of the cases was there evidence of medial hypertrophy (the range of normal values for medial thickness of muscular pulmonary arteries being taken as $2 \cdot 8-6.8 \%{ }^{3}$ ). The presence of thrombosis in these arteries was also noted. An examination was made of pulmonary arterioles less than $80 \mu \mathrm{m}$ in diameter, away from their immediate origin from parent muscular pulmonary arteries, to see whether they had a distinct medial coat of smooth muscle. At this diameter normal arterioles of healthy lowlanders do not have such a muscular coat. In none of the seven cases examined was there muscularisation of pulmonary arterioles.

In all seven cases the medial thickness of pulmonary veins between 100 and $500 \mu \mathrm{m}$ in external diameter was examined in the paraffin sections of the lung tissue, which had been fixed in collapse as described above. As in the case of the arteries, the medial thickness was expressed as a percentage of the external diameter of the vessel examined. Up to 50 pulmonary veins were available for study in each case. In contrast to the mensuration of pulmonary arteries, the measurement of the medial thickness in pulmonary veins is exceedingly difficult to carry out with sufficient accuracy to justify firm conclusions. While the internal lamina of small pulmonary veins is distinct no external elastic lamina exists as such. Concentric irregular elastic fibres gradually blend with adventitial connective tissues so that the precise location of the external limit of the media tends to be somewhat subjective. In addition, the ready collapse of the veins renders the lumina irregular in shape. In the present study measurements were made independently by two observers to avoid personal bias. The mean medial thickness of small pulmonary veins obtained by this method in each of the seven cases is shown in table 2 . In none of the cases was there evidence of medial hypertrophy of pulmonary veins (the normal value at sea level being taken as $\left.2 \cdot 6 \%{ }^{4}\right)$.

\section{Discussion}

These seven case reports confirm that the organs which bear the brunt of damage due to acute exposure to the hypobaric hypoxia of high altitude are the lungs and brain. As early as 1913 Ravenhills $^{5}$ gave an account of the clinical picture' of acute mountain sickness, or "puna" as it was known in Bolivia, which clearly distinguished between pulmonary and cerebral forms. His description underlined the role of oedema in the condition and what he called puna of cardiac and nervous types are sometimes today termed high altitude pulmonary and cerebral oedema, although it has been argued that pulmonary and cerebral acute mountain sickness are more suitable terms. ${ }^{6}$ Often both brain and lungs are equally seriously affected (cases 5 and 6), but sometimes the oedema is predominantly pulmonary (case 7) or cerebral (case 1).

The aetiology of high altitude pulmonary oedema is complex and it is not the purpose of this paper to give an account of investigations into its nature. Fluid retention may contribute, with antidiuretic hormone playing a part, ${ }^{7}$ although haemodynamic factors and possibly alteration of capillary membrane permeability by factors released from white cells or platelets are also likely to be important. Histological examination of the lung shows considerable dilatation of pulmonary capillaries and the presence of oedema coagulum in the alveolar ducts and spaces, many of which are lined by hyaline membranes similar to those found in the respiratory distress syndrome of the newborn..$^{89}$ There may be haemorrhage into the alveolar spaces and there is dilatation of pulmonary lymphatics and interstitial pulmonary oedema. Haemodynamically the condition is characterised by pulmonary arterial hypertension with a normal left atrial pressure,$^{1011}$ suggesting that there may be increased vascular resistance situated in the pulmonary venous capillaries. We have been able to demonstrate endothelial oedema vesicles in the pulmonary capillaries of rats in which simulated high altitude pulmonary oedema was induced. ${ }^{12}$ There is increased capillary permeability to protein.

None of the cases we studied showed increased medial thickness or crenation of elastic laminae of the small pulmonary arteries to suggest hypertrophy or sustained hypoxic pulmonary vasoconstriction. Furthermore, none of them had muscularisation of pulmonary arterioles. Such muscularisation of pulmonary arteries and arterioles has been reported previously in cases of high altitude pulmonary oedema but it almost certainly represents the natural muscularity of the distal portion of the pulmonary arterial tree in native highlanders, which is a marker of hypobaric hypoxia rather than of the onset of the disease. ${ }^{8}$ All seven trekkers reported here were Caucasian lowlanders with a naturally thin pulmonary vasculature. Moreover, these men had been taken to a lower altitude and treated with oxygen before the material became available for examination, which would allow any pulmonary vasoconstriction present during the attack to subside.

It has been suggested that constriction of pulmonary veins may play a part but we have found no morphological evidence in the present cases to sup- 
port this view. As with their arterial counterparts, the pulmonary veins of lowlanders on a short visit to the Himalayas are naturally very thin walled, with little propensity for significant constriction. There is some evidence that the pulmonary veins of native highlanders are naturally muscular and thus possess some potential for vasoconstriction. ${ }^{4}$ Nevertheless, we believe that there are great difficulties in determining medial thickness of pulmonary veins accurately and results should be accepted with considerable reserve.

We have given a full account of the clinical features of high altitude pulmonary oedema elsewhere ${ }^{8}$ but it should be noted that the cough is at first dry, and then productive of a foamy white sputum that is only rarely associated with haemoptysis in our experience. Sometimes the radiological changes are predominantly unilateral. ${ }^{18}$

Some salutary lessons about risk factors emerge from the clinical history in case 7 . This patient had already suffered from one recent attack of high altitude pulmonary oedema, from which he had been fortunate enough to recover and which he chose to ignore. Although the condition was diagnosed and treated correctly and promptly, with immediate descent to a lower altitude, he died. Some people are particularly susceptible to the disease and one attack should be a contraindication to further ascents to considerable heights.

The fatal outcome of the second attack in case 7 was likely to have been related to the development of pulmonary thrombosis. Another factor may have been the history of systemic hypertension, which may have raised pulmonary capillary pressure with incipient left ventricular failure. Evidence of preexisting heart disease with cardiomegaly was also found in cases 2 and 5 . It is remarkable that the former subject, a man of 38 years, had been climbing vigorously at $5180 \mathrm{~m}$ with severe narrowing of the left coronary artery. High altitude pulmonary oedema and cerebral oedema are commonly regarded as particular hazards for young adults and children, ${ }^{8}$ but only one of the seven cases we report was in a young man (case 3 ); the other men were in or approaching middle age. Possibly in older people, as in this series, thrombosis plays a prominent part in the disease process. Recognition of these factors of age and the associated likelihood of pre-existing heart disease could be important in view of the increasing numbers of middle aged or even elderly people, perhaps with a history of some previous heart disease, who are now encouraged to join treks.

Cerebral oedema was the important finding in cases 1, 5, and 6. Houston and Dickinson ${ }^{13}$ have summarised the evidence that this is the basis for one malignant form of acute mountain sickness. It commonly leads to severe headache, vomiting, ataxic gait, papilloedema, and coma. Less frequent features are hallucinations, blurred vision, speech difficulty, urinary incontinence, cranial nerve palsies, hemiparesis, rigidity or flaccidity, convulsions, and visual field defects. ${ }^{1}$ From the morbid anatomical aspect, there is swelling and flattening of the cerebral gyri and compression of the sulci. There is often herniation of cerebellar tonsils and unci (case 5). There are frequently small petechial haemorrhages (fig 5). Histologically the brain shows spongiosis (fig 4). In addition to oedema, haemorrhage, and other structural abnormalities, functional defects-for example, in neurotransmitter synthesis and release-may play a part in the causation of the symptoms.

Cerebral signs and symptoms developing on acute ascent to high altitude may be due to a cerebrovascular accident, such as thrombosis or haemorrhage, rather than to cerebral oedema, although the two may be linked. In cases 2 and 3 there was thrombosis of the cerebral veins and dural venous sinuses. In the latter case possibly cerebral oedema had led to compression of the dural sinuses, leading to consequent slowing and impairment of the blood flow through them with formation of venous thromboses and haemorrhages into the brain.

Pulmonary arterial thrombosis was prominent in four of the seven cases $(2,3,4$, and 7$)$. In one (case 4) deep vein thrombosis in the calf had occurred in addition. The importance of thrombosis in some cases of acute mountain disease is not widely appreciated. Ward ${ }^{14}$ gives an account of serious thrombotic incidents occurring in high altitude climbers, such as thrombophlebitis in the calf followed by pulmonary thromboembolism, pulmonary thrombosis and infarction, and hemiplegia following cerebral thrombosis. The episodes took place in young men of 23-41 years. Such thrombosis is not confined to Caucasians but has led to cases of hemiplegia in Sherpas. ${ }^{14}$ It is well known that disturbances of the coagulation of blood occur in man at high altitude and we give an extended account of the factors concerned in this elsewhere. ${ }^{8}$

In brief, the blood platelet count falls in men ascending to high altitude ${ }^{15}$ and in mice subjected experimentally to reduced barometric pressure. ${ }^{16}$ Decompression per se may lead to a sharp fall in the platelet count and the thrombocytopenia appears to be due in part to a reduction in platelet half life and in part to sequestration in the pulmonary circulation. ${ }^{15}$ At high altitude there is no ultrastructural abnormality of the thrombocytes. Genton and his colleagues found that calves at high altitude show the same thrombocytopenia and the same striking decrease in platelet half life. ${ }^{17}$ In these animals there 
is a great rise in the number of circulating young adhesive platelets, and they found a considerable shortening of the first stage of clotting or thromboplastin formation. Most of the information we have on disturbances of blood coagulation in man at high altitude comes from Indian studies and particularly from the work of Singh and Chohan. ${ }^{18}$ They have found that in Indian soldiers at high altitude there is a significant increase of plasma fibrinogen levels and fibrinolytic activity. In soldiers who develop clinical evidence of pulmonary hypertension, however, plasma fibrinogen levels are lower, suggesting that in them there is a constant depletion of fibrinogen by its conversion into fibrin. This mirrors the finding of diminished plasma fibrinogen levels in the calves referred to above. In cases of high altitude pulmonary oedema there appears to be a breakdown of the fibrinolytic system, resulting in an increase in plasma fibrinogen levels and in the time required for lysis of clot in venous blood. ${ }^{19}$ These disorders of blood coagulation probably account for the intravascular sludging of erythrocytes and the formation of fibrin thrombi within the pulmonary vasculature in high altitude pulmonary oedema. ${ }^{20}$

In people exposed to high altitude the resulting hypercoagulability of the blood and sequestration of platelets in the pulmonary vascular bed provokes pulmonary thrombosis. In the present cases such thrombosis was acute but, should it be extensive and affect the small pulmonary arteries over a prolonged period, it might be expected to lead to significant pulmonary vascular disease and pulmonary arterial hypertension. Singh ${ }^{21}$ reports the development of thrombotic, occlusive hypertensive pulmonary vascular disease of this type in Indian soldiers. This pulmonary hypertension persists at sea level. Singh and Chohan ${ }^{18}$ also refer to the development of thrombosis in the peripheral and splenic veins and in the coronary, cerebral, and mesenteric arteries, usually a few weeks after arrival at high altitude. Recognition of the importance of thrombosis brings into question the wisdom of the use of powerful diuretics such as frusemide in the treatment of pulmonary acute mountain sickness. Their dehydrating effect could initiate or aggravate thrombosis. We have gained the personal impression that thrombosis is more important in the pathogenesis of high altitude related disease in the Himalayas than in the Andes but can offer no explanation for this.

All but one of the men (case 5) developed bronchopneumonia and in two of them (cases 1 and 4) it was severe. Most patients with high altitude pulmonary oedema, if it is not reversed, develop bronchopneumonia. In case 4 its causation is not so clear cut. This man had ascended to an altitude of only $2440 \mathrm{~m}$ when he became ill and possibly his worse- ning chest infection culminating in confluent bronchopneumonia was the direct result of exposure to the harsh mountain environment and bathing in glacial rivers. On the other hand, fatal cases of high altitude pulmonary oedema on Mount Kenya have occurred after swimming in the icy water of the high altitude tarns $\mathrm{s}^{22}$ and possibly in the present case the bronchopneumonia was secondary to such oedema. Again, the bronchopneumonia may have developed secondarily to the widespread pulmonary arterial thrombosis, as appears to have occurred also in case 2 . In case 4 there was some uncertainty about the nature of the thrombi in the pulmonary vessels. They could have been autoch thonous or the result of thromboemboli secondary to thrombophlebitis of the deep veins of the left calf. Certainly this man did not have pulmonary oedema on admission to hospital for the chest radiograph was normal. The clinical features were more in keeping with cerebral oedema and this was confirmed at necropsy.

We appreciate that the material presented here is highly selective in the sense that it represents a few fatal cases of a condition that is usually trivial and so widespread as to affect about half of all those who ascend to high altitude. Nevertheless, these cases illustrate the devastating events that may overtake the middleaged trekker who fails to follow the ground rules. Some of these men (for example, cases 2 and 7) flew from low altitudes to high mountainous regions from which to start their trek. Thus they arrived at high altitude unacclimatised. A leaflet of the Himalayan Rescue Association gives advice on high altitude sickness for trekkers proceeding above $3660 \mathrm{~km}$ : "The golden rule is "Don't go too fast too high" (sic). Beware of the 'do or die' attitude in the Himalayas. All too often it has meant more 'die' than 'do.'" Several of the subjects in this series actually climbed to higher altitudes after developing symptoms such as vomiting (case 2 ) or breathlessness and tiredness (case 4) and this may have cost them their lives.

We wish to thank Drs BB Baidya and WM Bond, who carried out the necropsies at Shanta Bhawan Hospital.

\section{References}

${ }^{1}$ Dickinson JG. Severe acute mountain sickness. Postgrad Med J 1979;55:454-8.

${ }^{2}$ Hackett PH, Rennie D, Levine HD. The incidence, importance and prophylaxis of acute mountain sickness Lancet 1976;ii:1149-55.

${ }^{3}$ Harris P, Heath D. The human pulmonary circulation. 2nd ed. Edinburgh: Churchill Livingstone, 1977. 
${ }^{4}$ Wagenvoort CA, Wagenvoort N. Pulmonary veins in high-altitude residents: a morphometric study. Thorax $1982 ; 37: 931-5$.

${ }^{5}$ Ravenhill TH. Some experience of mountain sickness in the Andes. J Trop Med Hyg 1913;16:313-20.

- Dickinson JG. Terminology and classification of acute mountain sickness. $\mathrm{Br}$ Med J 1982;285:720-1.

7 Singh I, Khanna PL, Srivastava MC, Lal M, Roy SB, Subramanyam CSV. Acute mountain sickness. $N$ Engl $J$ Med 1969:280:175-84.

${ }^{8}$ Heath D, Williams DR. Man at high altitude. 2nd ed. Edinburgh: Churchill Livingstone, 1981.

${ }^{9}$ Arias-Stella J, Krüger H. Pathology of high altitude pulmonary edema. Arch Pathol 1963;76:147-57.

${ }^{10}$ Fred HL, Schmidt AM, Bates T, Hecht MM. Acute pulmonary edema of altitude. Clinical and physiologic observations. Circulation 1962;25:929-37.

$"$ Peñaloza D, Sime F. Circulatory dynamics during high altitude pulmonary edema. Am J Cardiol 1969;23:369-78.

12 Heath D, Moosavi H, Smith P. Ultrastructure of high altitude pulmonary oedema. Thorax 1973;28:694 700.

${ }^{13}$ Houston CS, Dickinson, JG. Cerebral form of high altitude illness. Lancet 1975 ;ii:758-61.

${ }^{14}$ Ward M. Mountain medicine. A clinical study of cold and high altitude. London: Crosby Lockwood Staples, 1975.
${ }^{15}$ Gray GW, Bryan AC, Freedman MH, Houston CS, Lewis WF, McFadden DM, Newell G. Effect of altitude exposure on platelets. J Appl Physiol 1975;39:648-51.

${ }^{16}$ Birks JW, Klassen LW, Gurney CW. Hypoxia-induced thrombocytopenia in mice. $J$ Lab Clin Med 1975;86:230-8.

17 Genton E, Ross AM, Takeda YA, Vogel JHK. Alterations in blood coagulation at high altitude. In: Vogel JHK, ed. Hypoxia, high altitude and the heart. Advances in Cardiology 5. Basel: S Karger 1970:3240.

${ }^{18}$ Singh I, Chohan IS. Blood coagulation changes at high altitude predisposing to pulmonary hypertension. $\mathrm{Br}$ Heart J 1972;34:611-7.

${ }^{19}$ Singh I, Chohan IS. Abnormalities of blood coagulation at high altitude. Int J Biomet 1972;16:283-97.

${ }^{20}$ Nayak NC, Roy S, Narayaran DCP. Pathologic features of altitude sickness. Am J Pathol 1964;45:381-91.

${ }^{21}$ Singh I. Pulmonary hypertension in new arrivals at high alitude. Proceedings of World Health Organisation meeting on primary pulmonary hypertension, October 1973. Geneva: WHO, 1974

${ }^{22}$ Horrobin DF, Cholmondeley HG. High altitude pulmonary oedema: pathophysiology and recommendations for prevention and treatment. East Afr Med J 1972;49:327-31. 